\title{
Geostatistics Studies and Geochemical Modeling Based on Core Data, Sheytoor Iron Deposit, Iran
}

\author{
Aref Shirazi ${ }^{1}$, Adel Shirazy ${ }^{2}$, Shahab Saki ${ }^{1}$ and Ardeshir Hezarkhani ${ }^{1}$ \\ 1. Mining and Metallurgical Engineering Department, Amirkabir University of Technology, Tehran 1591634311, Iran \\ 2. Faculty of Mining, Petroleum and Geophysics Engineering, Shahroud University of Technology, Shahrood 3619995161, Iran
}

\begin{abstract}
In general, the purpose of the mineralization modeling is the advancement of a mineral exploration project and ultimately, the extractive design of a deposit, which is one of the most important stages in mining engineering. Mineralization modeling is divided into two general categories, superficial and deep modeling. In surface modeling, the aim is finding abnormal locations in terms of mineralization at the study area, which is commonly used in the early stages of exploration as one of the means for locating exploratory boreholes. After drilling in the study area with the aim of identifying mineralization and reserve estimation it is necessary to obtain deep mineralization position and its geometric features, using statistical and modeling methods. Using mathematical, statistical and modeling methods, we can predict the position of iron mineralization in places where drilling is not done and eventually reach a three-dimensional model of the mineral materials underground. As a case study, the deep information about the boreholes of the sheytoor mining area in Yazd province of Iran was investigated. Iron mineralization was modeled as 2D cumulative model and 3D block model, and the results were presented. Finally the geochemical threshold and the anomalous limit of iron element are calculated by concentration-volume $(\mathrm{C}-\mathrm{V})$ fractal method in this deposit. Geochemical threshold and the anomalous limit for Fe in this deposit are $24.7 \%$ and $34.3 \%$ respectively.
\end{abstract}

Key words: Ore modeling, C-V fractal method, iron deposit, core data, sheytoor.

\section{Introduction}

Data processing means categorizing and converting them into an interpretable way. This is done by adjusting the information in the database and generating intelligible information by applying various mathematical, statistical, drawing up a variety of charts [1]. Nowadays, by providing new statistical and mathematical methods, especially with the introduction of computers into the field of modeling, quantitative and more precise models of mineral deposits have been prepared. Similarly, algorithms have been used to compute traditional handwriting methods, although caution should be considered in the application of computer methods [2]. In this study, after receiving the analysis results as raw data, at first censored data were investigated and normalization of raw data was done.

Corresponding author: Ardeshir Hezarkhani, Ph.D., professor, research fields: geochemistry, geology, mineal exploration, mining engineering.
At this stage, the database consists of the coordinates of each sample, the raw data values and the normalized raw data values. Using concentration-volume $(\mathrm{C}-\mathrm{V})$ fractal method, geochemical threshold and the anomalous limit are calculated and finally iron mineralization was modeled [3].

\section{1 Geolocation of Sheytoor Iron Deposit}

The sheytoor iron deposit is in Yazd province of Iran and is located $78 \mathrm{~km}$ from Bafq city, near the Gazestan village. The area of the deposit is approximately 28 $\mathrm{km}^{2}$.

You can see the eastern view of the Sheytoor region in Fig. 1 [4].

\section{Geology}

\subsection{Geological Setting}

The area is located in Yazd province and in central tectonic zone of Iran, which is a small part of the 
Poshtebadam-Bafq block. In terms of lithology, it has a wide range of alkaline (gabbro-diabaz) to acidic (rhyolitic and rhyodactic) rocks, and includes intrusive, semi-deep and extrusive types. Eastern view of the region and the position of the drilling equipments is shown in Fig. 2.

In Fig. 2, the locating of 1:1,000 map of sheytoor deposit and 1:20,000 map of the gazestan in the topographic map of 1: 50,000 sheytoor is shown [3,4].

\subsection{Stratigraphic Units}

In terms of lithology, the area consists of the late precambrian to cambrian volcanic-sedimentary rocks and igneous rocks after that. In the central parts of the region, diorite-gabbro and diabase masses occur as dykes and sills, with porphyritic granite and granite-syenite which cut out older rocks and outcrop. Parts of the ore are covered by present sediments. Metasomatic rock is as host of mineralization and mineralization has occurred inside it $[3,4]$.

\subsection{Mineralization}

Mineralization of iron-phosphate is closely related to the region's rocks including gabbro, monzo gabbro, diorite, syenite and diabase which is seen in dark green color. The main ore deposit is as apatite-magnetite mineralization.

Quartz and calcite constitute the main waste material of the mineral. The ore mainly consists of magnetite-apatite in the southern part, usually composed of quartz and calcite in the late stages after mineralization, and different forms occur within volcanic rocks, microgranite and granodiorite intrusive masses.

Based on microscopic and XRD analysis, the ore minerals include: magnetite, hematite, limonite, goethite, lipidocrocyte, apatite, pyrite, chalcopyrite and rare earth elements minerals such as monazite which can be seen in conjunction with pyroxene, actinolite, thermolite, epidote, chlorite, quartz and calcite waste minerals [4] (Fig. 3).

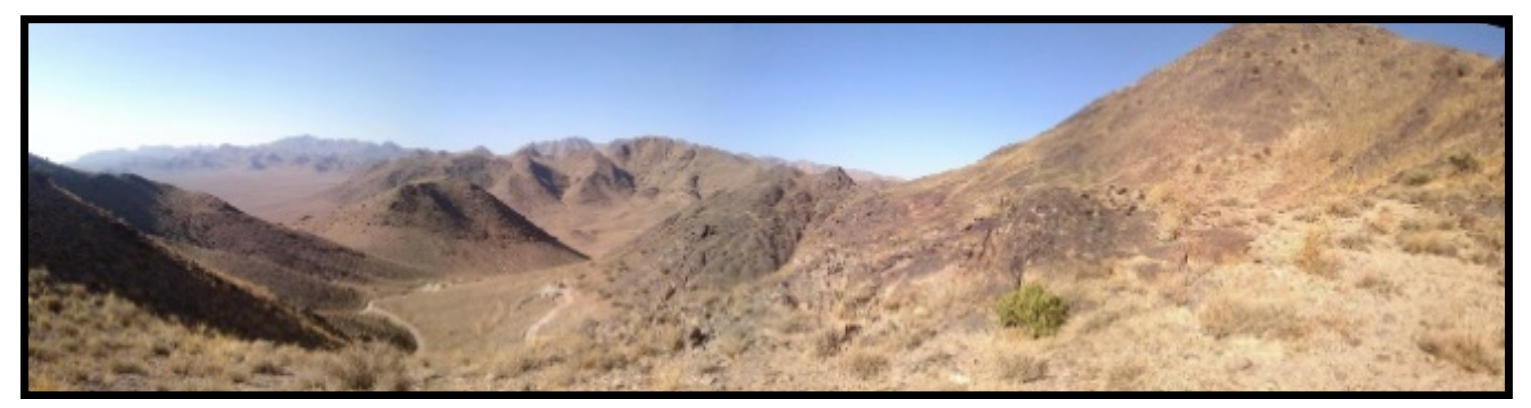

Fig. 1 Eastern view of the Sheytoor region.

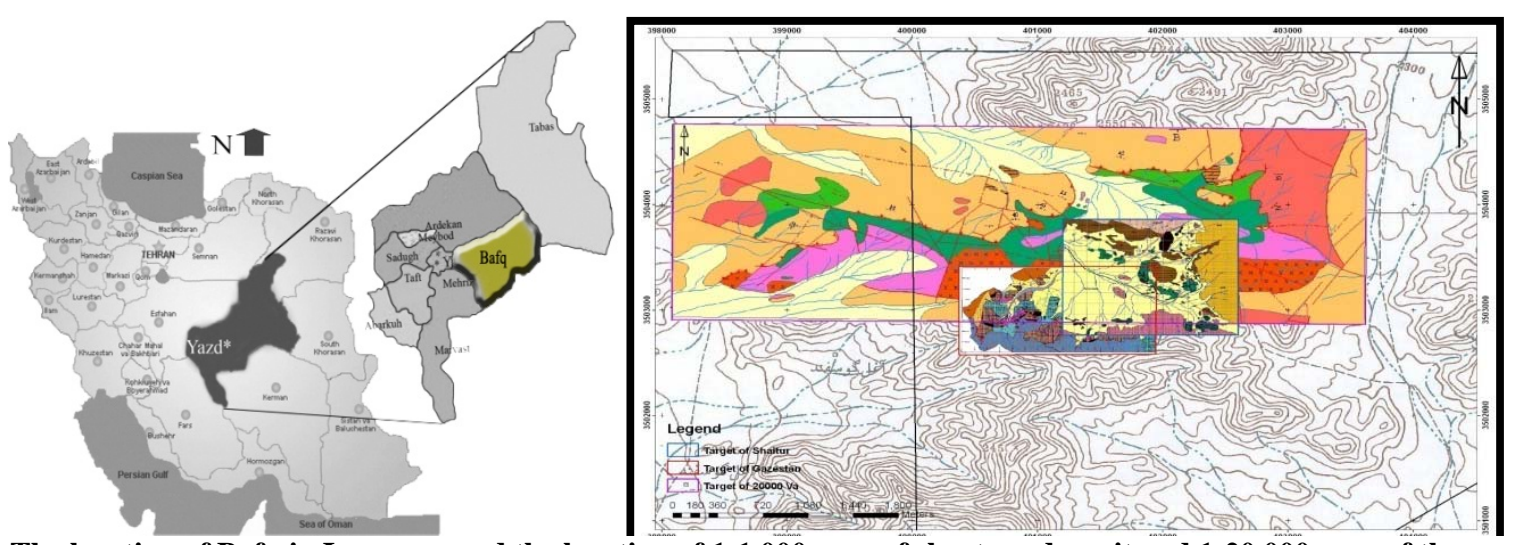

Fig. 2 The location of Bafq in Iran map and the locating of 1:1,000 map of sheytoor deposit and 1:20,000 map of the gazestan in the topographic map of 1: 50,000 sheytoor [4]. 


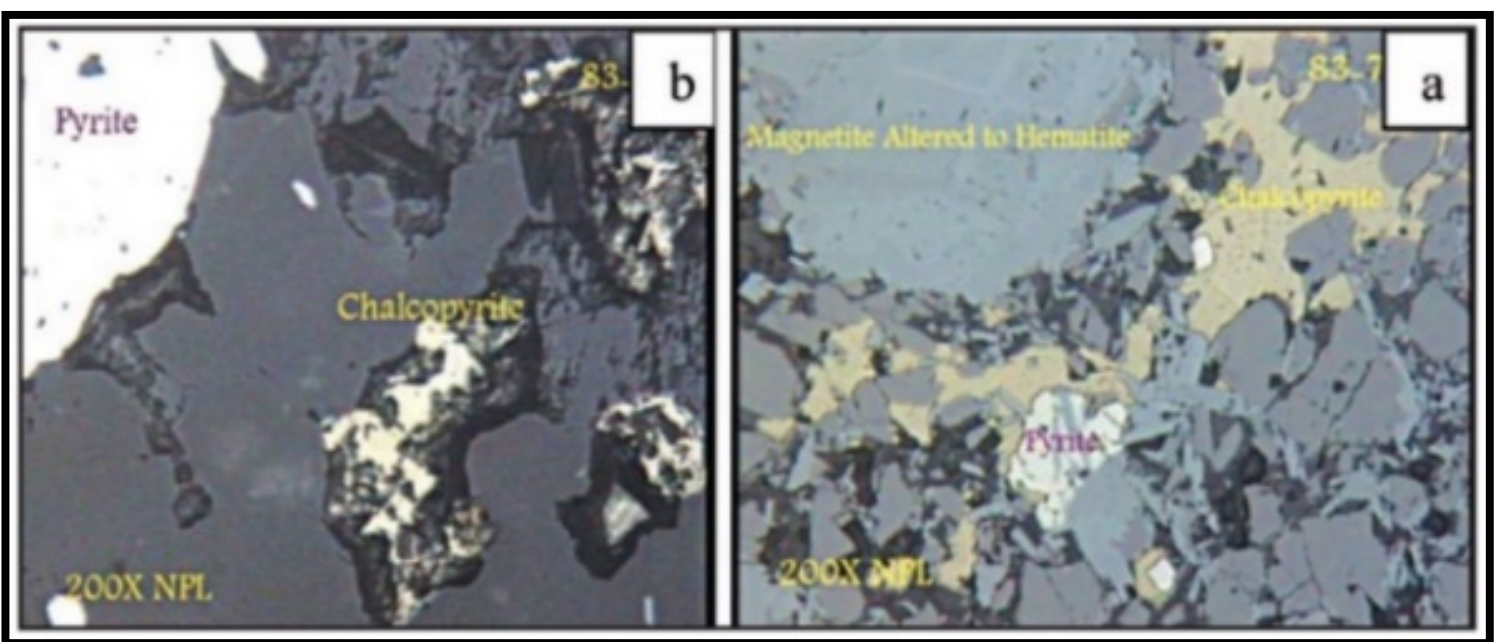

Fig. 3 Microscopic images of some ores of the region. (a) Magnetite, hematite, pyrite and chalcopyrite; (b) pyrite and chalcopyrite [4].

\section{Materials and Methods}

\subsection{Raw Data Preparation Methods}

Before using raw data censored outlier data must be identified and replaced. Censored data are said to be data among them, due to the high sensitivity limit of measuring devices, a number of data are found to be smaller than the device sensitivity limit. Such data can make statistical problems, Because, firstly, statistical methods require a complete set of non-censored data, and secondly, in some cases, such as anomaly separation from background and relative measurements, the existence of censored data leads to inappropriate evaluations. If the censored data are identified and replaced, the amount of background and intensity of the anomalies will be calculated more accurately [5].

As the existence of censored data among geochemical data leads to errors, outlier data also have the same effect on the results. In statistics, an outlier is an observation point that is distant from other observations $[6,7]$. An outlier may be due to variability in the measurement or it may indicate experimental error; the latter are sometimes excluded from the data set [8]. An outlier can cause serious problems in statistical analyses. Outliers can occur by chance in any distribution, but they often indicate either measurement error or that the population has a heavy-tailed distribution.

Several methods can detect and replace censored and outlier data. In this study, a simple method is used to replace sensor data. In this method, the values of less than sensitivity limit are replaced by $3 / 4$ of data value. The main problem of this method is that it is by no means influenced by the statistical parameters of the data society and is merely a function of the sensitivity limit of the measurement method $[5,9]$.

In order to identify and replace the outlier data, the doerffel method was used. Doerffel has prepared a graph for determining the threshold of outlier data values, which is provided for two levels of significance of 5\% and $1 \%$ (see Fig. 4) [4, 9].

To perform the doerffel test, the average $(\bar{x})$ and standard deviation of the data $(s)$ is calculated regardless of the largest amount of data. Then the largest amount of data $\left(x_{\mathrm{A}}\right)$ is considered to be outside of the row if it is true in the following equation:

$$
x_{A} \geq \bar{x}+s . g
$$

where " $g$ " is the threshold limit for outlier values which can be calculated by graph shown in Fig. 4.

\subsection{Estimation Methods in Modeling}

In this study, in order to grade estimation, methods kriging and inverse distance weighting (IDW) were used. 


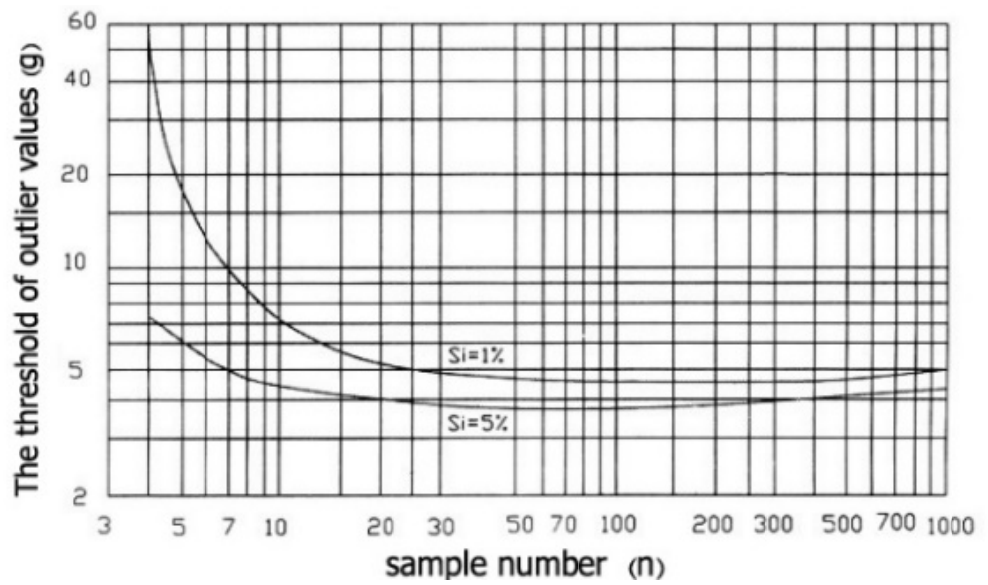

Fig. 4 The threshold of outlier values $(g)$ as a function of the sample number $(n)$ and the level of trust.

Kriging: The basic idea of kriging is to predict the value of a function at a given point by computing a weighted average of the known values of the function in the neighborhood of the point. In geostatistical models, sampled data are interpreted as the result of a random process. The fact that these models incorporate uncertainty in their conceptualization does not mean that the phenomenon - the forest, the aquifer, the mineral deposit - has resulted from a random process, but rather it allows one to build a methodological basis for the spatial inference of quantities in unobserved locations, and to quantify the uncertainty associated with the estimator. The kriging function is defined as follows:

$$
\hat{z}(x)=\sum_{i=1}^{n} \lambda_{i} z\left(x_{i}\right)
$$

$\lambda_{i}$ is the weight associated with the value of the $x$-variable $x$ at the point $i$ in the case where $\Sigma \lambda=1$ [10].

Inverse Distance Weighting (IDW): IDW is a type of deterministic method for multivariate interpolation with a known scattered set of points. The assigned values to unknown points are calculated with a weighted average of the values available at the known points. IDW is an interpolation method in which estimation is performed based on the values of the nearest points to the point of the weighted inverted distance. The calculation method of the IDW is as follows [11]:

$$
\begin{gathered}
W(x, y)=\sum_{i=1}^{N} \lambda_{i} w_{i} \\
\lambda_{t}=\frac{\left(\frac{1}{d_{i}}\right)^{p}}{\sum_{k=1}^{N}\left(\frac{1}{d_{k}}\right)^{p}}
\end{gathered}
$$

\subsection{Three-Dimensional Modeling}

3D modeling is one of the most common types of modeling to understand the mineralization model below the surface of the earth. This modeling, carried out by interpolation of the concentrations of borehole elements at different depths, results in a form of ore below the surface of the earth. Considering the threshold limit, it is possible to see the separated part of the deposit, which is considered as an anomaly. The most common type of 3D model for the description of the ore and the implementation design is "Regular 3D Fixed Block Model". Fig. 5 shows an example of a block model [2].

\subsection{Two-Dimensional Cumulative Modeling}

An important discussion that gives us a comprehensive view is the modeling of the deposit in a two-dimensional cumulative model. In this method of modeling, the total amount of iron in the depths of the earth is depicted on the surface. Therefore the position of the ore is visible on the ground. Using this model, it 


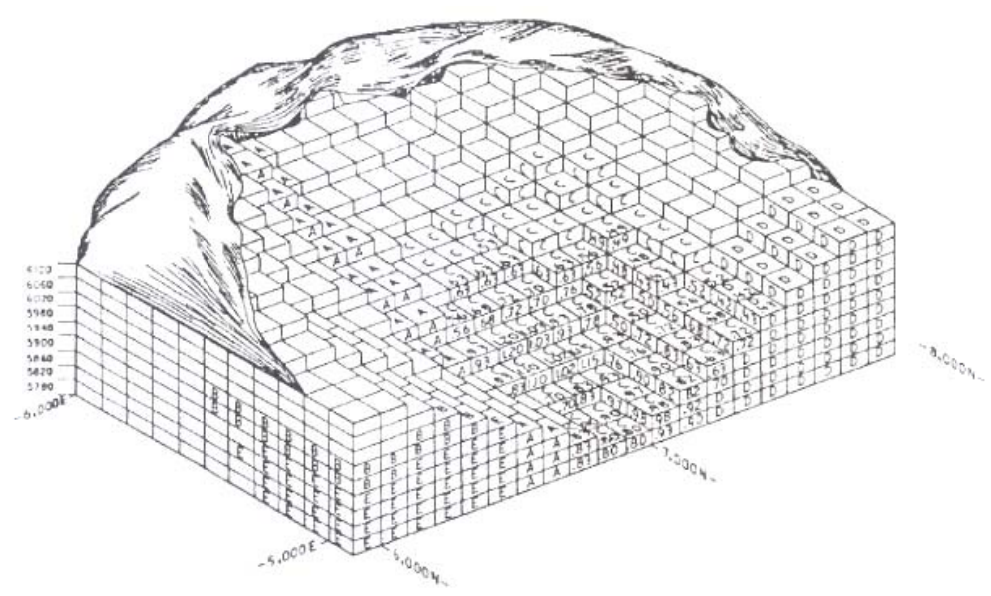

Fig. 5 Regular 3D Fixed Block Model [2].

is easy to determine the position of the facility and the depot of minerals and wastes. Other use of this model is in the extractive design of open mines in order to better design the position of the mine pit $[3,12]$.

\subsection{Concentration-Volume Fractal Method}

The $\mathrm{C}-\mathrm{V}$ fractal model, which was proposed by Afzal et al. [13] for division of mineralized zones and barren host rocks in porphyry deposits, can be addressed as:

$$
V(\rho \leq v) \propto \rho^{-\alpha_{1}} ; \quad V(\rho \geq v) \propto \rho^{-\alpha_{2}}
$$

where $V(\rho \leq v)$ and $V(\rho \geq v)$ illustrate two volumes with concentration values less than or equal to and greater than or equal to the contour value $\rho$; $v$ indicates the threshold value of a mineralized zone (or volume); and $\alpha_{1}$ and $\alpha_{2}$ are characteristic exponents. Elemental threshold values in this model represent boundaries between different mineralized zones and host rocks of mineral deposits. To calculate $V(\rho \leq v)$ and $V(\rho \geq v)$ which are the volumes enclosed by a contour level $\rho$ in a 3D block model, the borehole data of ore element concentrations were interpolated by utilization of geostatistical estimation [13, 14].

The selection of breakpoints as threshold values appears to be an objective decision because geochemical populations are defined by different line segments in the C-V log-log plot. The straight fitted lines were obtained based on least-square regression
$[15,16]$. In other words, the intensity of element enrichment is depicted by each slope of the line segment in the C-V log-log plots [17].

\subsection{Drilling and Sampling}

In this study, information of 20 boreholes which are drilled in Sheytoor deposit was used. The depth of the boreholes was between 99 and $430 \mathrm{~m}$. And 151 samples from cores were systematically collected, the average sampling distance was about $2 \mathrm{~m}$. All samples were analyzed using ICP-AES method [4]. You can see the geolocations of boreholes in Fig. 6 .

The statistical parameters of the statistical society such as mean, standard deviation, variance etc. were calculated and shown in Table 1 [3].

\section{Discussion}

\subsection{Censored and Outlier Data}

The explained method in Section 3.1 was used to replace the $\mathrm{Fe}$ censored data values. Using Doerffel method for identifying outliers, data were analyzed. Regarding iron cadmium data, the values of $42.10 \%$ were considered as larger values and then the average and standard deviations of data were calculated without considering these values, which was $24.78 \%$ and $9.91 \%$, respectively.

According to the graph that is given in Fig. 4 and number of samples (151 samples), the amount of (g) 

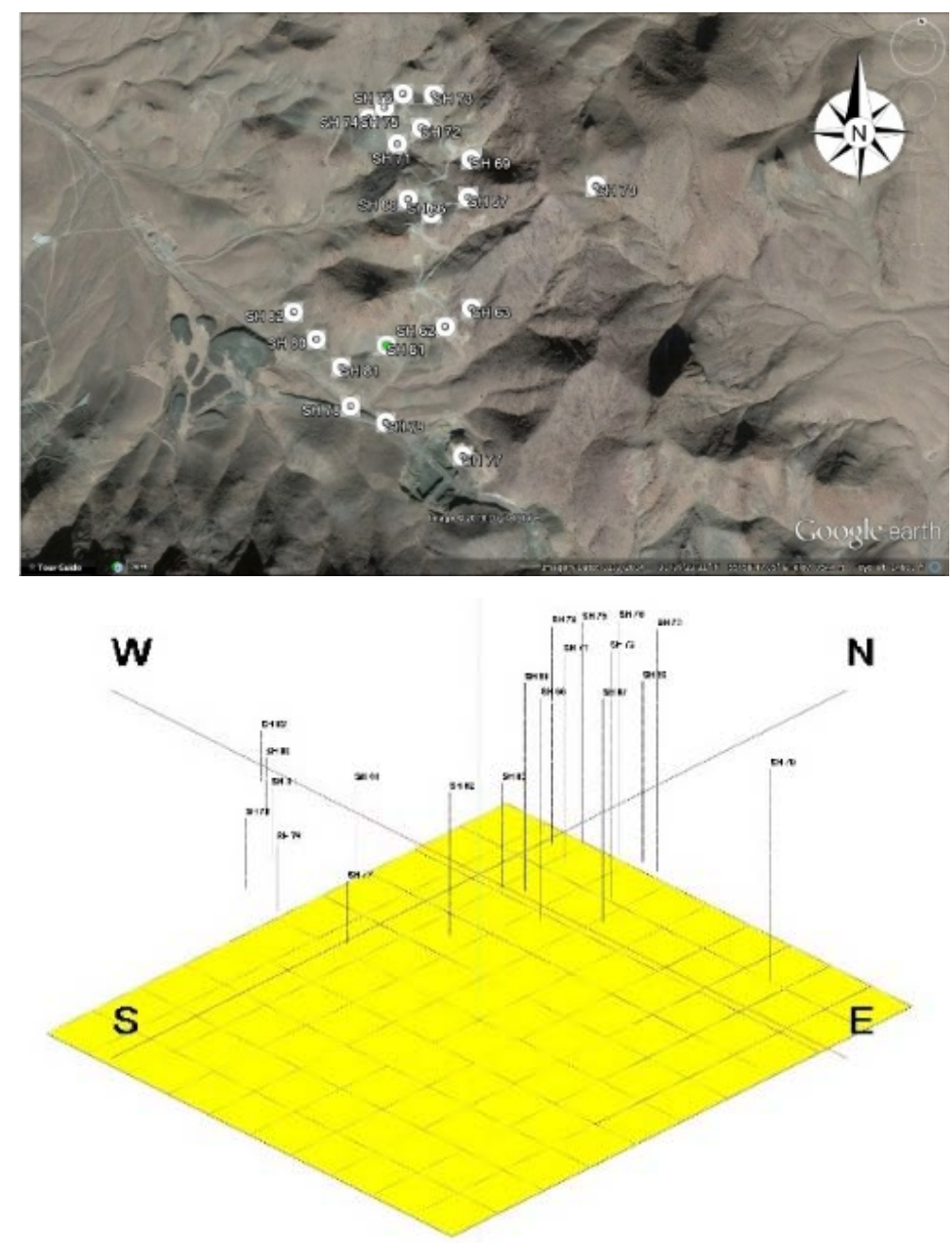

Fig. 6 Geolocation of drilled exploratory boreholes in the Sheytoor deposit at surface and depth.

Table 1 Statistical parameters of the statistical society.

\begin{tabular}{lllllllll}
\hline $\begin{array}{l}\text { Sample } \\
\text { number }\end{array}$ & $\begin{array}{l}\text { Minimum } \\
(\%)\end{array}$ & $\begin{array}{l}\text { Maximum } \\
(\%)\end{array}$ & Mean (\%) & Median (\%) & Variance (\%) & $\begin{array}{l}\text { Standard } \\
\text { deviation (\%) }\end{array}$ & Skewness & Kurtosis \\
\hline 151 & 4.98 & 64.47 & 32.77 & 30.9 & 231.03 & 15.19 & 0.06 & -1.15 \\
\hline
\end{tabular}

parameter, was estimated 4.4.

So using Doerffel relationship:

$$
x_{A} \geq \bar{x}+s . g
$$

Outlier limit $\geq 24.78+(9.91 \times 4.4)=68.38 \%$.

The highest Fe content in the analysis data is $65.5 \%$ which is less than outlier limit $(68.38 \%)$. Therefore, it does not count as an outlier value. So some value is not removed from the raw data as outlier data.

\subsection{Raw Data Computing}

In this section, the frequency distribution chart (histogram) is drawn to examine the various characteristics of our statistical society. The statistical society of the study is a set of geochemical information in the form of iron element concentration derived from systematic sampling of exploratory boreholes which are drilled in the sheytoor mining area. The histogram of our statistical society is shown in Fig. 7.

\subsection{D Block Model of Fe Mineralization}

In this model, by using the IDW interpolation method, interpolation and estimation of the iron element concentration according to the boreholes (Fig. 6) 


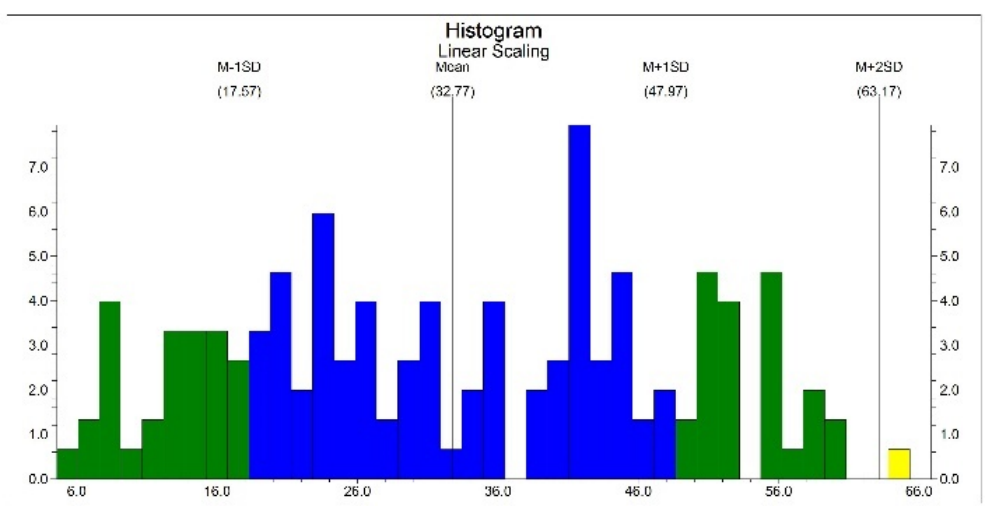

Fig. 7 Histogram of the data on a linear scale due to the sum of the mean with the standard deviation.

Top
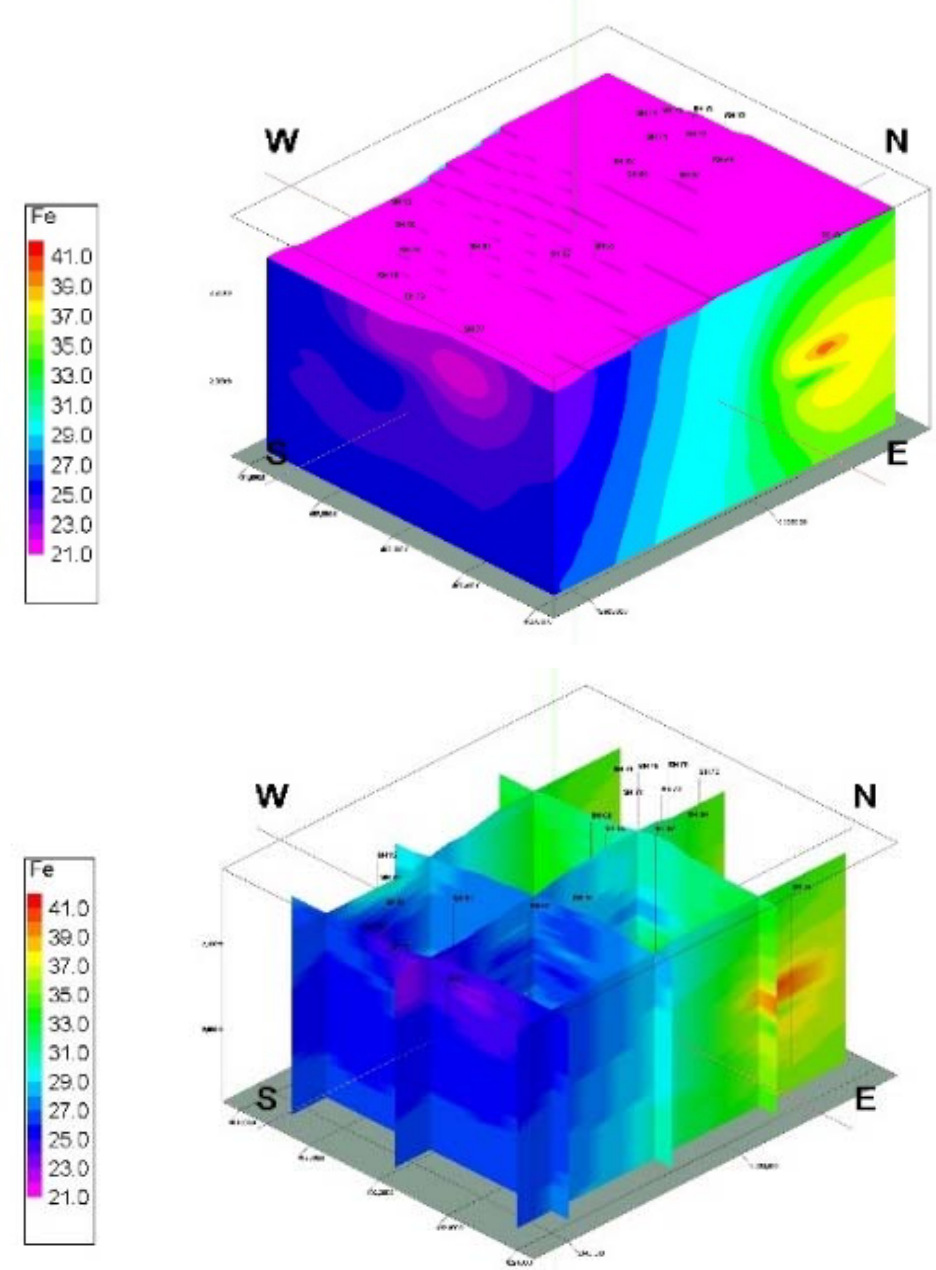

Fig. 8 3D block model of Fe mineralization in Sheytoor iron deposit, regardless of the cut-off grade. 
were studied at all points of the study area. Then, 3D block model of subsurface mineralization was modeled (Fig. 8).

\subsection{D Cumulative Model of Fe}

This type of modeling, known as two-dimensional cumulative modeling of the sub-surface deposit, can well represent the surface expansion of the ore. In this modeling method, the cumulative value of the element in question is calculated at each point of the desired range level due to the drilling and interpolation methods and is plotted as a map.

The Fe concentration at different points of the deposit was estimated using the kriging interpolation method. Then the cumulative content of the Fe was calculated in percentages at each point of the earth's surface. Finally, the two-dimensional cumulative map of the iron mineralization of the sub-surface deposit was modeled.

In a $2 \mathrm{D}$ cumulative model, in order to provide more practical visibility and reduce computations, the target area is divided into cells, and by applying interpolation methods, each cell is assigned a cumulative grade. Using this map, you can see the cumulative concentration of iron element on the surface of the Earth (Fig. 9).

\subsection{Modeling Based on C-V Fractal Method}

Fig. 10 shows the logarithmic graph of the volume of the $\mathrm{Fe}$ mineralization versus the $\mathrm{Fe}$ concentration in the ore deposit and the separation of communities in fracture sections of the data process.

According to the above graph, and determining the location of the fracture of the curve, each of them represents a different statistical society. Based on the concentration-volume fractal method, the geochemical threshold of the Fe element in the deposit was $24.7 \%$ and the anomalous limit in the deposit was $34.3 \%$. In Figs. 11 and 12, iron mineralization is modeled based on the geochemical threshold and anomalous limit respectively.

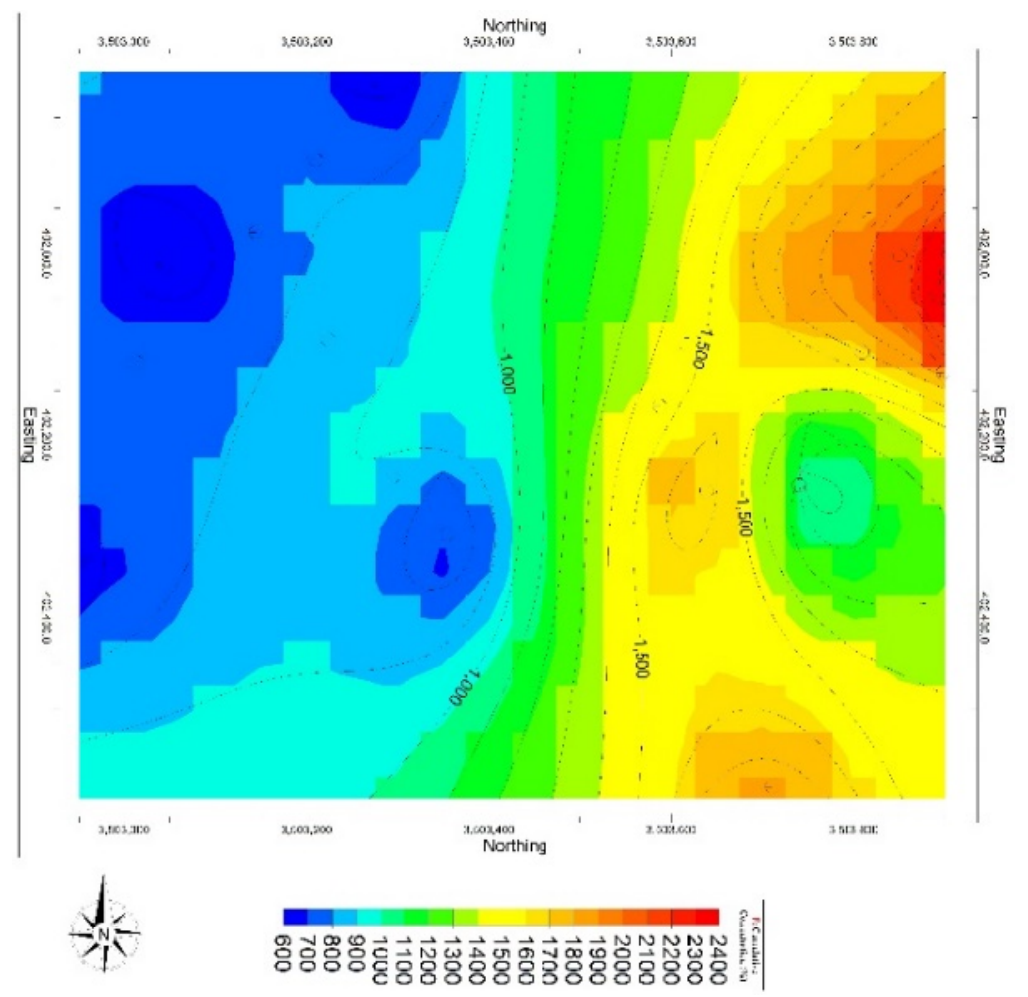

Fig. 9 Two-dimensional cumulative model of Fe mineralization in Sheytoor iron deposit. 


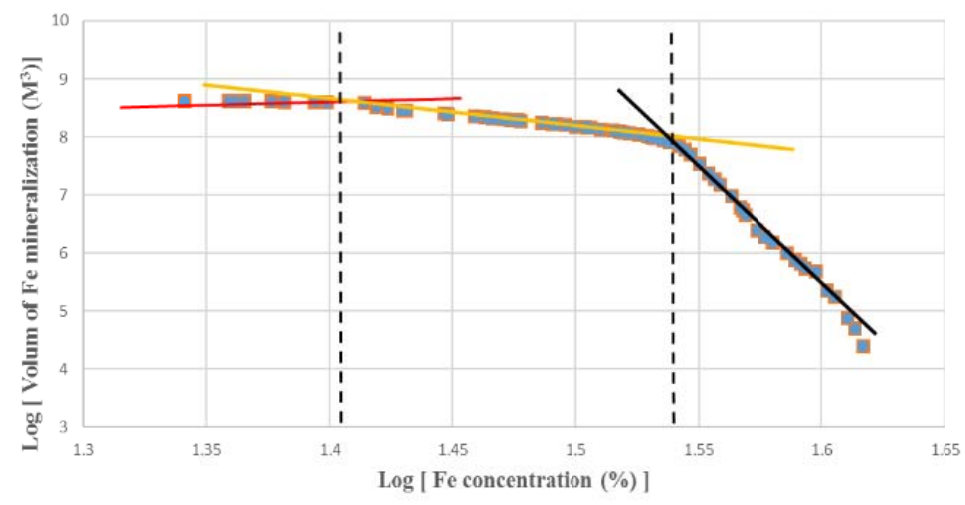

Fig. 10 Separation of communities in concentration-volume logarithmic graph, C-V fractal method.

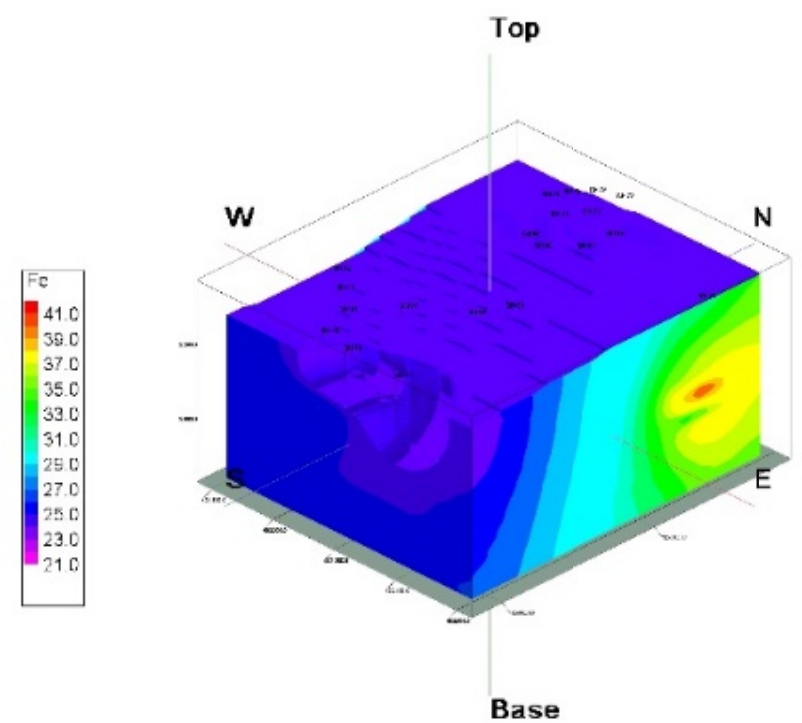

Fig. 11 Fe mineralization 3D model based on geochemical threshold, cut-off grade is $24.7 \%$.

Top

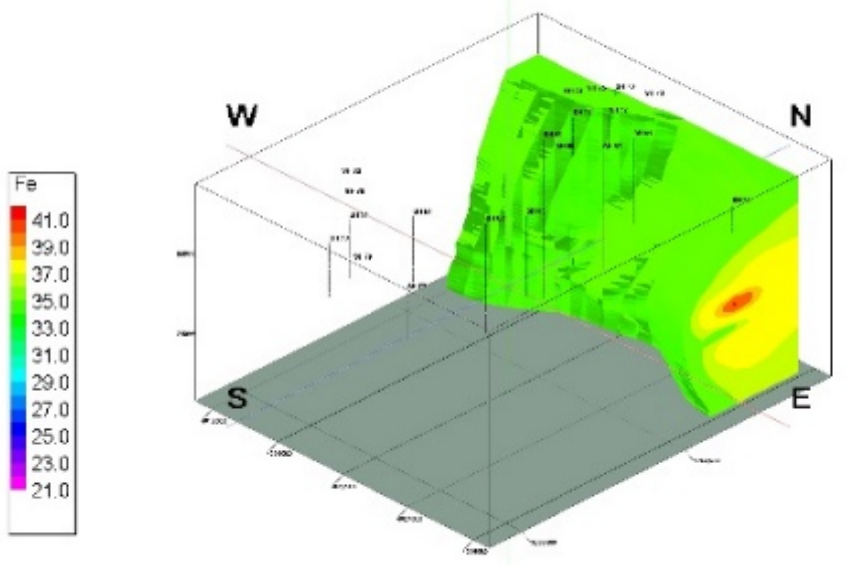

Base

Fig. 12 Fe mineralization 3D model based on anomalous limit, cut-off grade is $34.3 \%$. 


\section{Conclusions}

The region is located in Yazd province and in central tectonic zone of Iran. Statistical and geostatistical studies were carried out based on core data of Sheytoor iron deposit which is located near Bafgh city. The main ore deposit is as apatite-magnetite mineralization.

In order to identify and replace the outlier data, the doerffel method was used. It was found that there are no outlier data among the geochemical data of the iron element obtained from the analysis.

Using Kriging and IDW interpolation methods, 3D block model and 2D cumulative models were created and presented.

Using C-V fractal method, geochemical threshold and anomalous limit were estimated which are $24.7 \%$ and $34.3 \%$ respectively.

\section{References}

[1] Han, J., Pei, J., and Kamber, M. 2011. Data Mining: Concepts and Techniques. Elsevier.

[2] Ataeipoor, M. 2006. Basics of Mineral Modeling. Vol. 1. Amirkabir University of Technology (Tehran Polytechnic) Press.

[3] Shirazi, A. 2018. "Geochemical Investigations and Modeling on Sheytoor Iron Deposit, Bafq.” M.Sc. thesis, Amirkabir University of Technology (Tehran Polytechnic), Tehran.

[4] Yousefi, M. 2016. General and Detailed Exploration of Iron Ore Anomalies of Iran's Central Plateau, $5 a$ Anomlay (Sheytoor-Gazestan). Retrieved from Tehran.

[5] Hassanipak, A. A., and Sharafeddin, M. 2005. Exploration Data Analysis. Vol. 1. Tehran: Tehran University Press.

[6] Grubbs, F. E. 1969. "Procedures for Detecting Outlying Observations in Samples." Technometrics 11 (1): 1-21.

[7] Maddala, G. S. 1992. "Outliers." Introduction to Econometrics (2nd ed.). Vol. 1. New York: MacMillan. [pp. 23-42].
[8] Kalisch, M., Michalak, M., Sikora, M., Wróbel, Ł., and Przystałka, P. 2015. "Influence of Outliers Introduction on Predictive Models Quality." In Beyond Databases, Architectures and Structures. Advanced Technologies for Data Mining and Knowledge Discovery, Springer, pp. 79-93.

[9] Hassani Pak, A. 1998. Geostatistics. Tehran: University of Tehran: Persian.

[10] Cressie, N. 1990. "The Origins of Kriging." Mathematical Geology 22 (3): 239-52.

[11] Lu, G. Y., and Wong, D. W. 2008. "An Adaptive Inverse-Distance Weighting Spatial Interpolation Technique." Computers \& Geosciences 34 (9): 1044-55.

[12] Shirazi, A., Hezarkhani, A., and Shirazi, A. 2018. "Geochemical Modeling of Iron Mineralization in Sheytoor-Gazestan Area Based on core Data." Presented at the 3rd International Geosciences Congress, Iran, Tehran.

[13] Afzal, P., Alghalandis, Y. F., Khakzad, A., Moarefvand, P., and Omran, N. R. 2011. "Delineation of Mineralization Zones in Porphyry $\mathrm{Cu}$ Deposits by Fractal Concentration-Volume Modeling." Journal of Geochemical Exploration 108 (3): 220-32.

[14] Afzal, P., Ahari, H. D., Omran, N. R., and Aliyari, F. 2013. "Delineation of Gold Mineralized Zones Using Concentration-Volume Fractal Model in Qolqoleh Gold Deposit, NW Iran." Ore Geology Reviews 55: 125-33.

[15] Agterberg, F., Cheng, Q., Brown, A., and Good, D. 1996. "Multifractal Modeling of Fractures in the Lac du Bonnet Batholith, Manitoba." Computers \& Geosciences 22 (5): 497-507.

[16] Spalla, M. I., Marotta, A. M., and Gosso, G. 2010. Advances in Interpretation of Geological Processes: Refinement of Multi-Scale Data and Integration in Numerical Modelling. Society of London Special Publication, ISBN: 978-1-186239-295-3.

[17] Yasrebi, A. B., Afzal, P., Wetherelt, A., Foster, P., and Esfahanipour, R. 2013. "Correlation between Geology and Concentration-Volume Fractal Models: Significance for $\mathrm{Cu}$ and Mo Mineralized Zones Separation in the Kahang Porphyry Deposit (Central Iran)." Geologica Carpathica 64 (2): 153-63. 